\title{
An empirical comparison of population genetic analyses using microsatellite and SNP data for a species of conservation concern
}

\author{
Shawna J. Zimmerman ${ }^{1,2^{*}}$ (D, Cameron L. Aldridge ${ }^{1,2}$ and Sara J. Oyler-McCance ${ }^{1}$
}

\begin{abstract}
Background: Use of genomic tools to characterize wildlife populations has increased in recent years. In the past, genetic characterization has been accomplished with more traditional genetic tools (e.g., microsatellites). The explosion of genomic methods and the subsequent creation of large SNP datasets has led to the promise of increased precision in population genetic parameter estimates and identification of demographically and evolutionarily independent groups, as well as questions about the future usefulness of the more traditional genetic tools. At present, few empirical comparisons of population genetic parameters and clustering analyses performed with microsatellites and SNPs have been conducted.

Results: Here we used microsatellite and SNP data generated from Gunnison sage-grouse (Centrocercus minimus) samples to evaluate concordance of the results obtained from each dataset for common metrics of genetic diversity $\left(H_{\mathrm{O}}, H_{\mathrm{E}}, F_{\mathrm{IS}}, A_{\mathrm{R}}\right)$ and differentiation $\left(F_{\mathrm{ST}}, G_{\mathrm{ST}}, D_{\mathrm{J} \text { ost }}\right)$. Additionally, we evaluated clustering of individuals using putatively neutral (SNPs and microsatellites), putatively adaptive, and a combined dataset of putatively neutral and adaptive loci. We took particular interest in the conservation implications of any differences. Generally, we found high concordance between microsatellites and SNPs for $H_{E}, F_{I S}, A_{R}$, and all differentiation estimates. Although there was strong correlation between metrics from SNPs and microsatellites, the magnitude of the diversity and differentiation metrics were quite different in some cases. Clustering analyses also showed similar patterns, though SNP data was able to cluster individuals into more distinct groups. Importantly, clustering analyses with SNP data suggest strong demographic independence among the six distinct populations of Gunnison sage-grouse with some indication of evolutionary independence in two or three populations; a finding that was not revealed by microsatellite data.

\footnotetext{
* Correspondence: szimmerman@usgs.gov

${ }^{1}$ U.S. Geological Survey, Fort Collins Science Center, 2150 Centre Avenue, Bldg. C, Fort Collins, CO 80526, USA

${ }^{2}$ Department of Ecosystem Science and Sustainability and Natural Resource

Ecology Laboratory, Colorado State University, Fort Collins, CO 80526, USA
}

(c) The Author(s). 2020 Open Access This article is licensed under a Creative Commons Attribution 4.0 International License, which permits use, sharing, adaptation, distribution and reproduction in any medium or format, as long as you give appropriate credit to the original author(s) and the source, provide a link to the Creative Commons licence, and indicate if changes were made. The images or other third party material in this article are included in the article's Creative Commons licence, unless indicated otherwise in a credit line to the material. If material is not included in the article's Creative Commons licence and your intended use is not permitted by statutory regulation or exceeds the permitted use, you will need to obtain permission directly from the copyright holder. To view a copy of this licence, visit http://creativecommons.org/licenses/by/4.0/ The Creative Commons Public Domain Dedication waiver (http://creativecommons.org/publicdomain/zero/1.0/) applies to the data made available in this article, unless otherwise stated in a credit line to the data. 
(Continued from previous page)

Conclusion: We demonstrate that SNPs have three main advantages over microsatellites: more precise estimates of population-level diversity, higher power to identify groups in clustering methods, and the ability to consider local adaptation. This study adds to a growing body of work comparing the use of SNPs and microsatellites to evaluate genetic diversity and differentiation for a species of conservation concern with relatively high population structure and using the most common method of obtaining SNP genotypes for non-model organisms.

Keywords: Population structure, Population genetics, Evolutionarily significant units, Conservation, Genomics, Microsatellites, Single nucleotide polymorphisms

\section{Background}

Accurate estimation of population genetic parameters has become an important part of wildlife conservation [1]. Genetic characterization can be used to identify populations and understand gene flow [2-5]. More recently, genetic data have been used to begin to understand local adaptation [6-8] and to identify groups with distinct evolutionary or demographic characteristics [9-12]. Most past genetic studies of wildlife species have been accomplished with relatively few $(<20)$ highly variable microsatellite loci. Microsatellites, also called simple sequence repeats, were discovered in the 1980s and were quickly adopted as one of the most commonly used genetic markers [13, 14] because they tend to be highly polymorphic, are evenly distributed throughout the genome $[15,16]$, and are located in non-coding regions allowing the general assumption that neutral processes were being meausured. Unlike many other types of markers, microsatellites have a high mutation rate that is quite variable across different loci. This mutation rate is the result of slippage during DNA replication, a process that is not well understood [17]. The high mutation rate of microsatellites that results in highly informative markers may also lead to an underestimate of heterozygosity through homoplasy, or when two individuals have the same allelic state through independent mutation and not from a common ancestor [17]. Additionally, repeatability of genotyping across laboratories can be challenging [18-21] largely because allele size calls are somewhat subjective and size determination methods can impact inferred fragment size [22], even with use of automated software [23].

A single nucleotide polymorphism (SNP) is a location in the DNA sequence where individuals vary at a single nucleotide. Technological advancements have allowed creation of much larger SNP genotype datasets, greatly increasing the number of loci sampled with less effort and lower cost in comparison to microsatellite development and genotyping [16]. Because of their high prevalence in the genome and the potential to target functional regions, SNPs are predicted to replace microsatellites for genetic characterization [24]. SNPs are more abundant and uniformly distributed across the genome than microsatellites, and have a well-understood mutational mechanism with low levels of homoplasy [25], but they have lower allelic diversity [26]. Lower allelic diversity in comparison to microsatellites is expected, because a nucleotide base at a SNP can only be one of four possible states: A, T, C, or G. In reality, the natural pairing of certain bases in DNA structure and the low likelihood of multiple mutations at one location results in the majority of SNPs being biallelic. Because of the relatively low allelic diversity, equal distribution throughout the genome, ascertainment bias of highly polymorphic microsatellite regions, and relatively constant mutation rate of SNPs, some have argued that SNPs provide a more accurate representation of genome-wide variation $[27,28]$. Until recently, SNP datasets were only available for species with reference genomes, such as model organisms or important agricultural species. The development of reduced representation methods to obtain SNP genotypes without a reference genome has broadened the application of SNP markers to numerous species $[29,30]$. One of the main appeals of SNP loci is the ease with which high throughput/automatic analyses can be used in comparison with development and genotyping of microsatellites [24, 31, 32 resulting in the generation of large numbers of genotypes in a relatively short period of time and for minimal cost. Further, increasing the number of loci sampled is expected to increase precision of population genetic estimates [33, 34].

In addition to the potential improvement in precision of population parameter estimates from the increased number of loci, the explosion of genomic techniques and their application to non-model organisms has also led to the ability to ask new questions about conservation $[35,36]$. SNPs are found in coding and non-coding regions of the genome and they can represent both demographic (i.e., drift) and functional (i.e., selection) processes. Many authors have suggested that conservation units identified below the species level should incorporate an evaluation of demographic and evolutionary distinctness [37-41]. Defining genetically similar 
units for conservation can inform management actions (e.g., habitat restoration, translocation) or potentially impact legal protection status under the Endangered Species Act (ESA), which allows for the separate protection of geographically and ecologically distinct populations [42]. The predicted advantages to using SNP data as opposed to microsatellite data for conservation have lead us to question if microsatellites will be a useful tool in the future or will be completely replaced by SNP data.

Technological advancements in genomic approaches for non-model organisms has resulted in use of reduced representation sequencing methods to generate large SNP datasets for many wildlife species; datasets that are often archived and available for potential future use. Understanding how SNP data compare to inferences made from the more traditional microsatellite data is important for long-term genetic monitoring given the increasing trend of using SNP data for conservation objectives. Previous studies have compared the relative abilities of SNP and microsatellite loci to evaluate levels of relatedness [43-49], probability of identity and parentage [50$54]$, create linkage maps $[55,56]$, evaluate genetic diversity $[43,45,46,51,57-61]$, and detect low to mid levels of differentiation [45, 57-62]. Some studies have even used genome-wide SNP data to identify distinct population units $[11,12,63,64]$. Here we used SNP and microsatellite datasets from the same group of genetic samples from a species of conservation concern to empirically evaluate agreement across marker types for population genetic analyses and consider the potential consequences in conservation decision making. The samples we used are typical of many conservation studies: opportunistically collected, variable source, variable quality, and from multiple populations of variable size that are represented by variable numbers of samples. Additionally, we used previously identified candidate adaptive loci [65] to evaluate identification of distinct units using datasets composed of genetic markers reflecting different evolutionary processes.

The Gunnison sage-grouse (Centrocercus minimus) is a sagebrush obligate avian species listed as threatened under the Endangered Species Act in 2014. The species exists as a network of seven populations predominantly occurring in Colorado and a small portion of the range extending into Utah (Fig. 1) $[66,67]$. The majority of individuals in the species $(\sim 85-90 \%)$ are located in the Gunnison Basin population, which is largest in land area and highest in genetic diversity [69]. The six remaining satellite populations support much smaller numbers of birds; in descending order San Miguel Basin, Piñon Mesa, Crawford, Dove Creek-Monticello (Dove Creek from here on), Cerro Summit-Cimarron-Sims Mesa (Cimarron from here on), and Poncha Pass (Table 1) [70]. Genetic differentiation is high between all populations [69], local environmental conditions are variable [68], and there is some evidence of adaptive divergence among populations [65]. The Poncha Pass population is thought to have been extirpated in the 1970s, re-established with individuals translocated from Gunnison Basin, and currently persists as the result of on-going translocations [71]. Consequently, the Poncha Pass population was not included in the analyses presented here.

The double digestion RAD-Seq approach to reduced representation sequencing is one of the most commonly used genomic library preparations to generate SNP genotypes. With the increasing use of RAD-Seq generated SNPs instead of microsatellite data for conservation questions and monitoring, here we aim to compare population genetic parameters specifically from RADSeq generated SNPs and microsatellites. To date, few studies have compared the consequences of marker types in conservation objectives when a typical RAD-Seq protocol is used (though see [34, 45, 50, 51, 64]). Given the impact of decisions made during RAD-Seq protocols on downstream analysis [72], the prevalence of RAD-Seq generated SNP datasets, and the limited empirical examples of comparisons to more traditional microsatellite analyses, more comparisons can provide insight into the limitations or benefits of RAD-Seq generated SNP data and the future utility of microsatellite loci. Through previous studies on this species of conservation concern, we had access to two range-wide Gunnison sage-grouse genetic datasets, one of microsatellite [73] and one of SNP loci [65]. We had three specific objectives in this study: (1) compare genetic diversity metrics across datasets, (2) compare genetic differentiation metrics across datasets, and (3) compare clustering methods across datasets and investigate evidence of evolutionary independence among populations.

\section{Results \\ Genetic diversity}

For all diversity metrics, 95\% confidence intervals calculated from SNPs were narrower than confidence intervals from microsatellites (Fig. 2; Additional file 1: Table S1). Microsatellite estimates had large confidence intervals in all cases, which resulted in no significant differences among population estimates. In contrast, the narrower confidence intervals with SNPs resulted in significant differences between populations. Of the four metrics, $H_{\mathrm{O}}$ had the lowest correlation across marker type (Spearman $\rho=0.257$, Pearson $r=0.345$ ) (Fig. 2b). As theoretically expected, values of $H_{\mathrm{O}}$ from microsatellites in all populations were $\sim 0.500$ (range: $0.464-0.548$ ) while values from SNPs were lower, $\sim 0.200$ (range: 0.183-0.197; Fig. 2a). However, both marker types resulted in relatively consistent population ranks based on 


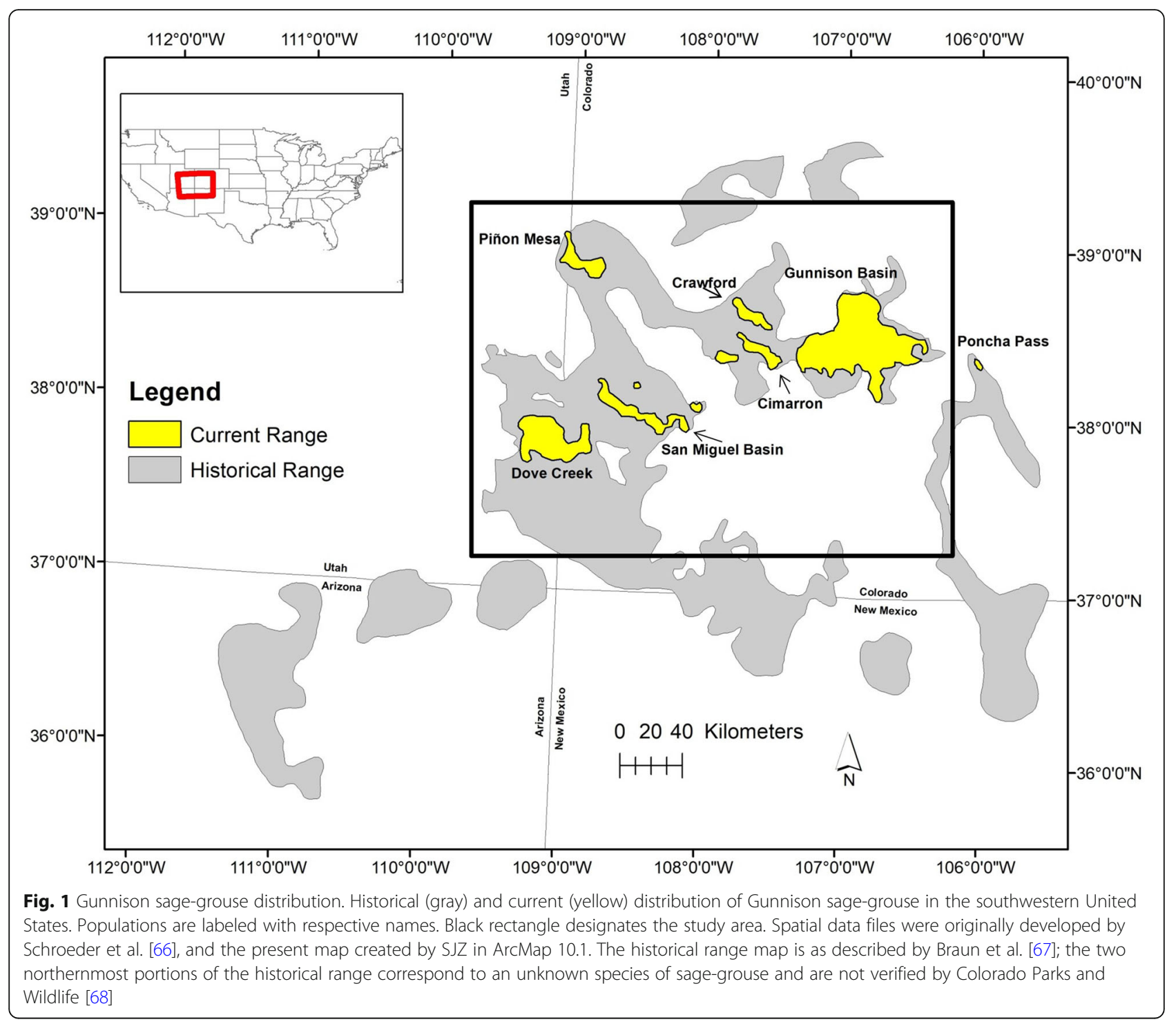

Table 1 Sample size for each population of Gunnison sagegrouse and each marker type

\begin{tabular}{llll}
\hline Population & \# Samples & & 2004 Pop. Est. \\
\cline { 2 - 3 } & MSAT & SNP & \\
\hline Cimarron & 4 & 4 & 74 \\
Crawford & 21 & 12 & 157 \\
Dove Creek & 43 & 12 & 98 \\
Gunnison Basin & 116 & 12 & 3978 \\
Piñon Mesa & 19 & 10 & 182 \\
Poncha Pass & 0 & 0 & 10 \\
San Miguel & 51 & 10 & 206 \\
\hline
\end{tabular}

MSAT microsatellites, SNP single nucleotide polymorphisms. Population estimates of the 2004 population size $=2004$ Pop. Est. [70] mean $H_{\mathrm{O}} \quad(p=0.031$, Wilcoxon paired signed-rank). Values of $H_{\mathrm{E}}$ showed high correlation (Spearman $\rho=$ 0.886 , Pearson $r=0.925$ ), and relative consistency in ranking populations across marker types $(p=0.031$, Wilcoxon paired signed-rank). The values for $H_{\mathrm{E}}$ were within similar ranges as $H_{\mathrm{O}}$, microsatellite estimates at 0.500 (range: $0.413-0.578$ ) and SNP estimates at $\sim 0.200$ (range: 0.154-0.194; Fig. 2c and d). Similarly, allelic richness showed high levels of correlation (Spearman $\rho=0.943$, Pearson $r=0.925$ ), and consistent ranking of populations by levels of genetic diversity ( $p=0.031$, Wilcoxon paired signed-rank) across marker type (Fig. 2e and f). Estimates of $F_{\mathrm{IS}}$ also showed relatively high correlation (Spearman $\rho=$ 0.600, Pearson $r=0.978$ ), however, ranking of 

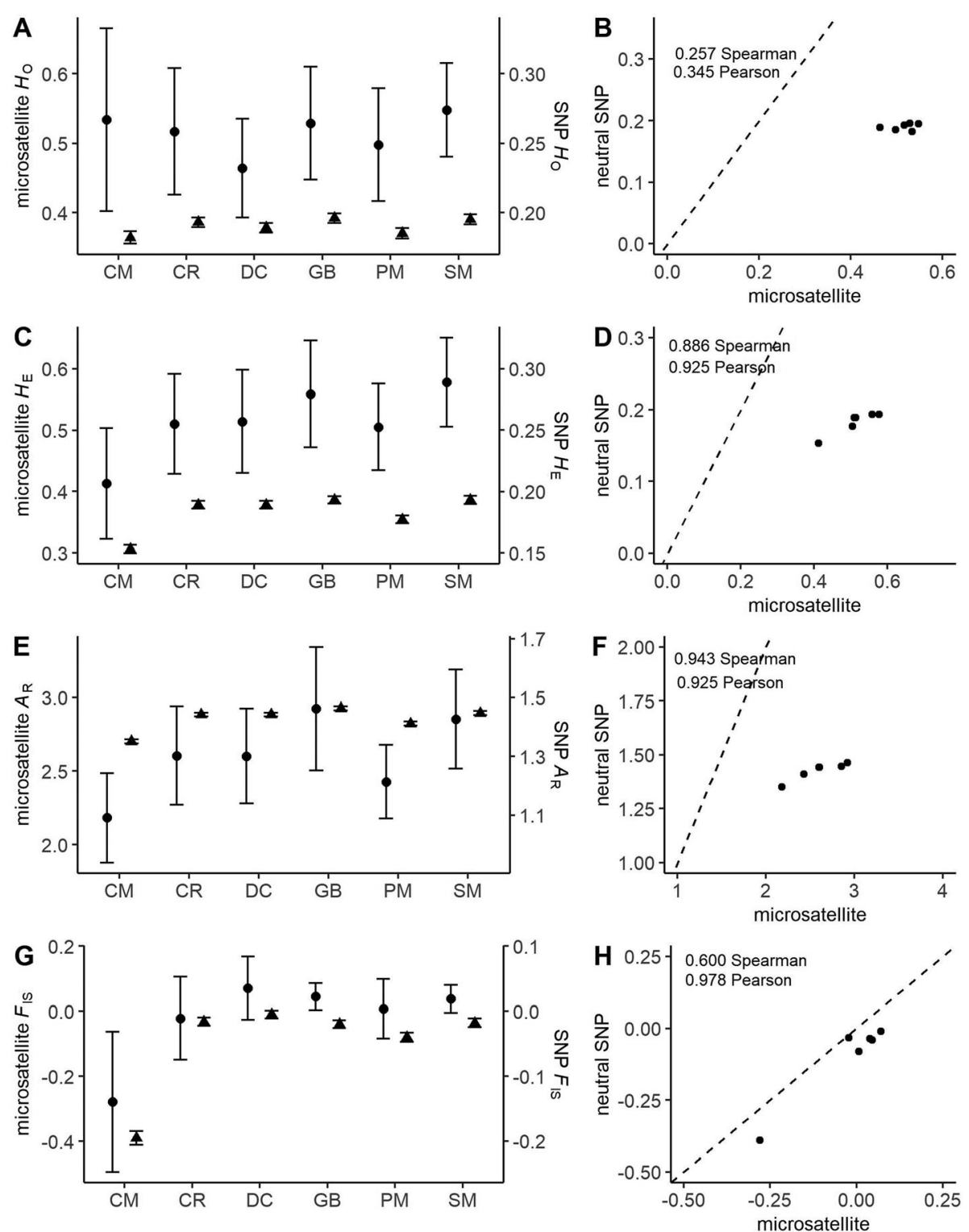

Fig. 2 Comparison of genetic diversity values for Gunnison sage-grouse populations. Confidence intervals (95\%) around mean values for microsatellite $(\bullet)$ and putatively neutral SNP $(\boldsymbol{\Lambda})$ loci were constructed. Estimates for observed heterozygosity $\left(H_{0} ; \mathbf{a}\right)$, expected heterozygosity $\left(H_{E} ; \mathbf{C}\right)$, allelic richness $\left(A_{R} ; \mathbf{e}\right)$, and inbreeding coefficient $\left(F_{I S} ; \mathbf{g}\right)$ are shown in the left-hand column. Populations are abbreviated along the $x$-axis: $\mathrm{CM}=$ Cimarron, $\mathrm{CR}=$ Crawford, $\mathrm{DC}=$ Dove Creek, $\mathrm{GB}=$ Gunnison Basin, $\mathrm{PM}=$ Piñon Mesa, $\mathrm{SM}=$ San Miguel. Relationships between estimates from microsatellites and SNPs for $H_{\mathrm{O}}(\mathbf{b}), H_{E}(\mathbf{d}), A_{R}(\mathbf{f})$ and $F_{I S}(\mathbf{h})$ are shown in the right-hand column. Spearman rank and Pearson's correlation coefficient are also included in the plots in the right-hand column. Dashed line corresponds to a 1:1 relationship

populations was not as consistent $(p=0.563$, Wilcoxon paired signed-rank) across marker types and the magnitude of the values for each marker type resulted in different inferences in some cases (Fig. $2 \mathrm{~g}$ and $\mathrm{h}$ ); microsatellites indicated outbred (minimum value: -0.279 ) to slightly inbred (maximum value 0.071) populations while SNPs indicated slightly to moderately outbred populations $(-0.194--0.004)$.

\section{Genetic differentiation}

Generally, genetic differentiation estimates from SNP datasets had narrower confidence intervals in comparison to estimates from microsatellites (Fig. 3; Additional file 1: Table S2) which were significantly correlated in all pair-wise comparisons (Mantel $r>0.9, p<0.001$ ). All differentiation metrics had a high correlation across marker types and datasets (Fig. 4). For $F_{\mathrm{ST}}$ and $G_{\mathrm{ST}}$, confidence 

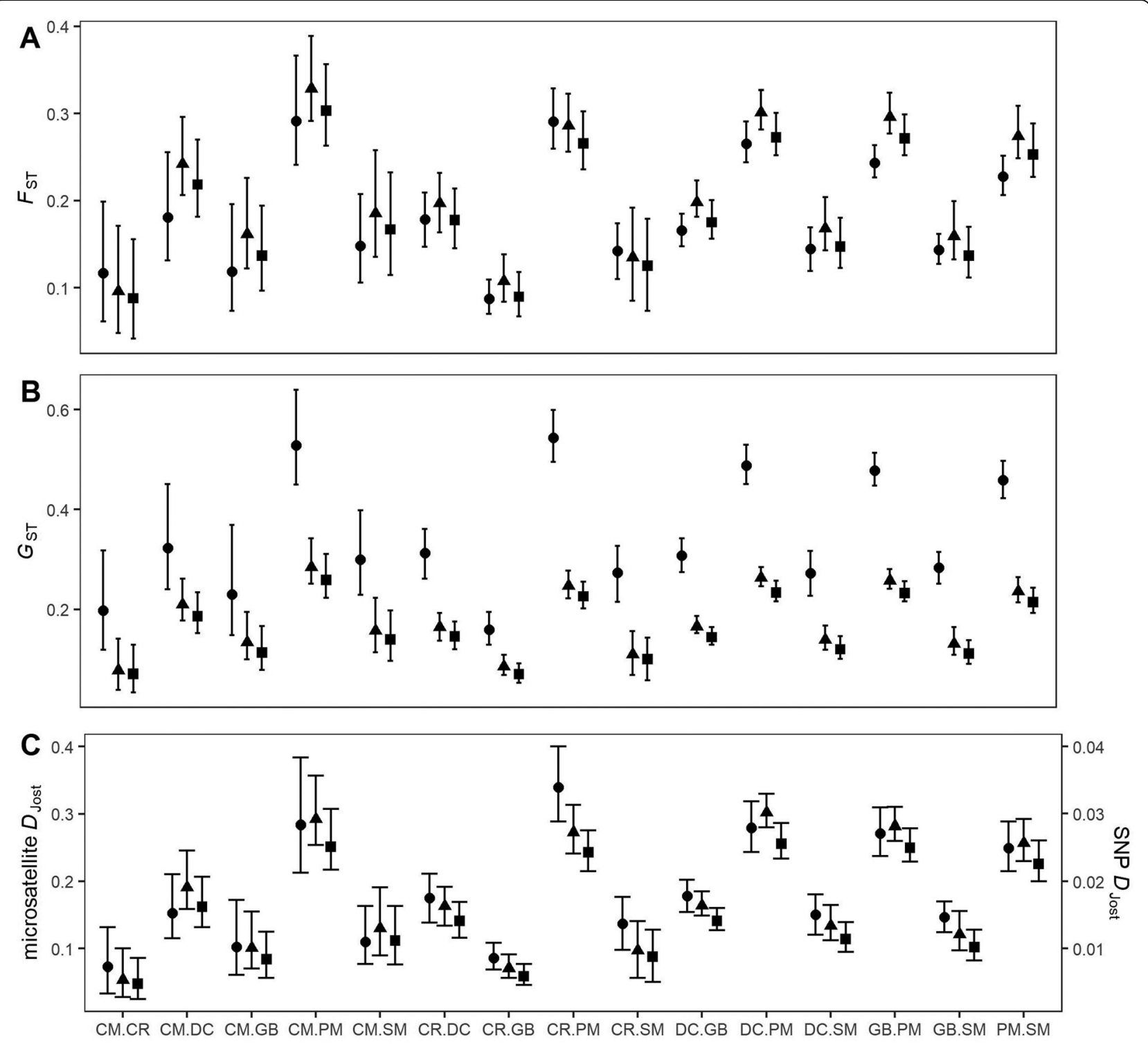

Fig. 3 Comparison of genetic differentiation values for pair-wise comparisons of Gunnison sage-grouse populations. Confidence intervals (95\%) around mean values for microsatellite $(\bullet)$, putatively neutral SNP $(\boldsymbol{\Delta})$, and all SNP $(\boldsymbol{\bullet})$ loci. Pair-wise estimates are for $F_{S T}(\mathbf{a})$, GST $(\mathbf{b})$, and $D_{\text {Jost }}(\mathbf{c})$. Populations in pair-wise comparisons are abbreviated along the $x$-axis: $C M=$ Cimarron, $C R=$ Crawford, $D C=$ Dove Creek, $G B=G u n n i s o n$ Basin, $\mathrm{PM}=$ Piñon Mesa, $\mathrm{SM}=$ San Miguel; $\mathrm{CM} \cdot \mathrm{CR}=\mathrm{F}_{\mathrm{ST}}$ between Cimarron and Crawford

intervals for population estimates from microsatellites and both SNP datasets typically overlapped (Fig. 3a and b). Estimates of $D_{\text {Iost }}$ from microsatellites and both SNP datasets did not overlap and the magnitude of microsatellite estimates were consistently much higher in comparison to SNP estimates (Fig. 3c), though the same general pattern remained (Fig. $4 \mathrm{c}$ and i). Similarly, values of $G_{\mathrm{ST}}$ estimated with microsatellites were also larger in magnitude than with SNPs, though to a lesser degree than observed with $D_{\text {Iost }}$ (Fig. 3b).

\section{Clustering}

The lowest BIC for hypothetical genetic clusters in DAPC corresponded to 6 groups with microsatellites $(\mathrm{BIC}=484.603), 5$ groups with all SNPs $(\mathrm{BIC}=454.768)$, and putatively adaptive SNPs $(\mathrm{BIC}=298.376)$, and 4 with putatively neutral SNPs $(\mathrm{BIC}=449.803)$. The optimal number of PCs to include in the DAPC analysis as determined by the a-score method was 22 for microsatellites, 6 for all SNPs, 5 for putatively neutral SNPs, and 6 for putatively adaptive SNPs. Clustering of individuals in 

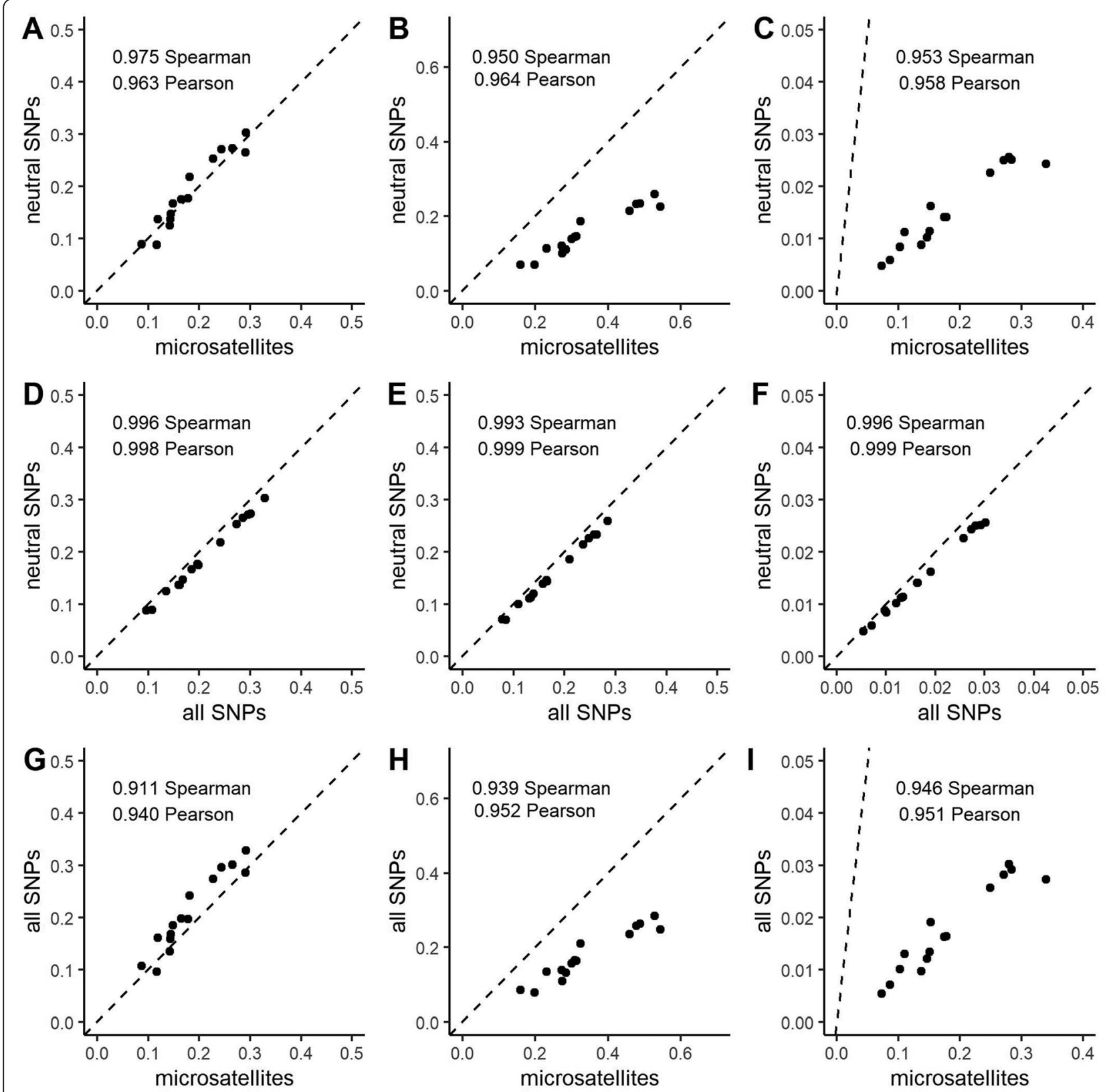

Fig. 4 Correlation of differentiation metrics for Gunnison sage-grouse populations. Relationships between estimates from different datasets: microsatellites, putatively neutral SNPS, and all SNPs for $F_{S T}(\mathbf{a}, \mathbf{d}, \mathbf{g}), G_{S T}(\mathbf{b}, \mathbf{e}, \mathbf{h})$, and $D_{\text {Jost }}(\mathbf{c}, \mathbf{f}, \mathbf{i})$ are shown in respective panels. Axes are labeled by dataset. Spearman rank and Pearson's correlation coefficient are included in the upper left-hand corner of each panel. Dashed line corresponds to a 1:1 relationship

DAPC with microsatellites identified Piñon Mesa as the only population that clearly separates from the other populations along discriminant function 1 (Fig. 5a), while discriminant function 2 pulls populations into identifiable groups though still with overlap (Fig. 5a). With all and putatively neutral SNPs, discriminant function 1 separates Gunnison Basin and Piñon Mesa from the other populations (Fig. $5 \mathrm{~b}$ and $\mathrm{c}$ ), and discriminant function 2 separates Dove Creek (Fig. $5 b$ and c). The candidate adaptive loci dataset shows Piñon Mesa and Dove Creek clearly separated along discriminant function 1, while San Miguel, Cimarron, Crawford, and Gunnison Basin cluster together (Fig. 5d).

The dendrogram created from microsatellite data generally grouped individuals into known populations where Cimarron, Crawford, and Gunnison Basin grouped closest together with Piñon Mesa, Dove Creek, and San Miguel grouping closer together but away from 


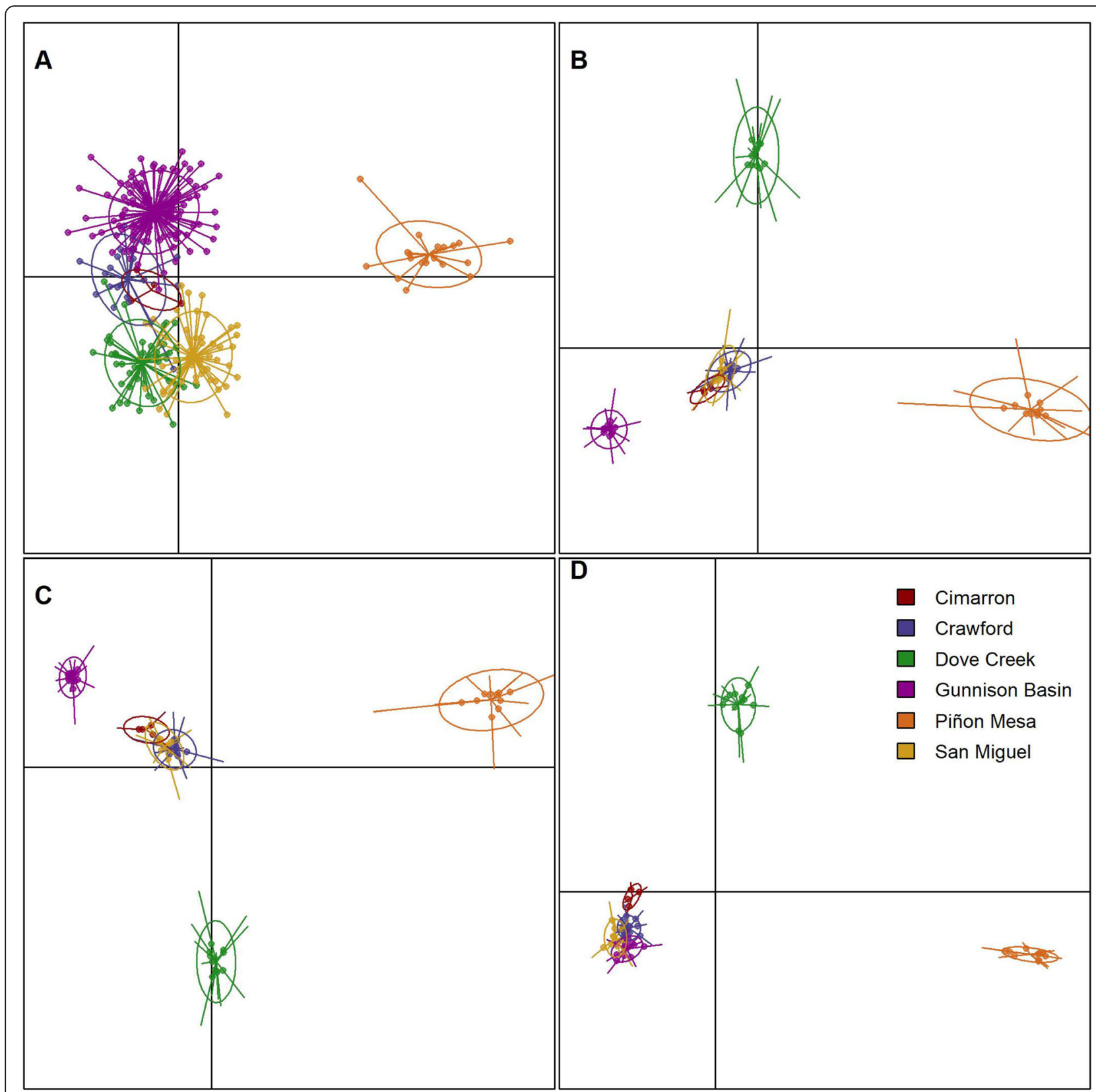

Fig. 5 Star-plots of DF1 (x-axis) and DF2 (y-axis) from discriminant analysis of principle components (DAPC) for Gunnison sage-grouse. Panels correspond to different datasets: a microsatellite, $\mathbf{b}$ all SNPs, $\mathbf{c}$ putatively neutral SNPS, $\mathbf{d}$ and candidate adaptive SNPs. Each point represents an individual color coded by sampling origin

the Cimarron, Crawford, Gunnison Basin individuals (Fig. 6a). Cimarron and Crawford individuals were grouped together on a single branch, along with two Gunnison Basin individuals. Additionally, two individuals from Gunnison Basin and an individual from San Miguel cluster with the Dove Creek individuals. Similar to the clustering pattern observed in DAPC, all SNPs and putatively neutral SNPs resulted in nearly indistinguishable grouping patterns where all populations are identifiable on individual branches (Fig. $6 \mathrm{~b}$ and c, respectively). With both the all SNP and putatively neutral SNP datasets Cimarron, Crawford, and Gunnison Basin group most closely, Piñon Mesa is the most distant from the center, and a single individual sampled in Crawford grouped with the San Miguel individuals. With neutral SNPs a single San Miguel individual grouped with Cimarron (Fig. 6c). Though similar to the other SNP dendrograms in that samples clustered into distinct 
A

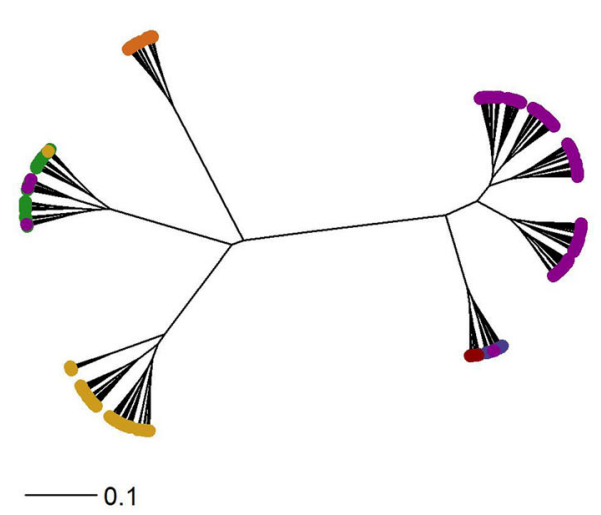

C

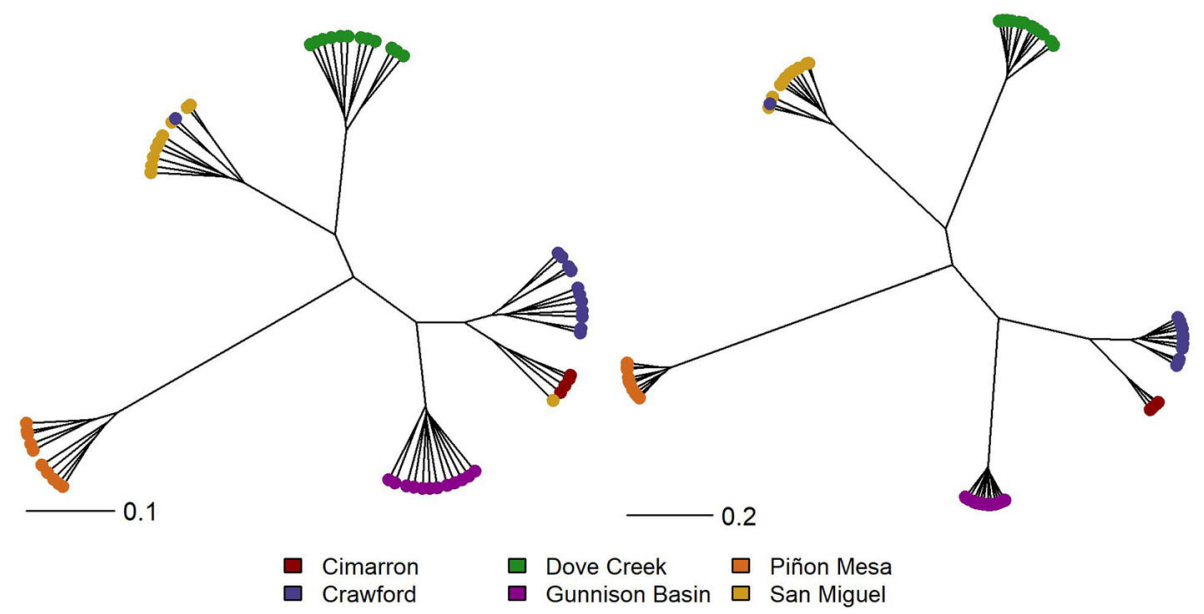

B

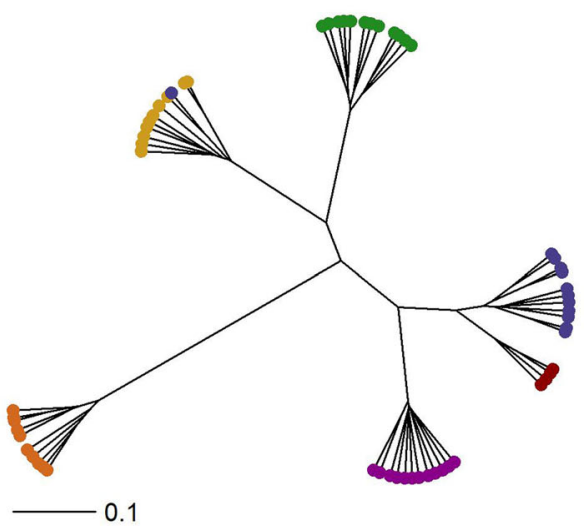

D

Fig. 6 Comparison of dendrograms of individual Gunnison sage-grouse using the hierarchical clustering method "ward. D2". Panels correspond to different datasets: microsatellites (a), all SNPs (b), putatively neutral SNPs (c), and candidate adaptive loci (d). Colors indicate sampling origin

populations, branch lengths appear somewhat longer in the candidate adaptive loci dataset (Fig. 6d). When considering hierarchical clustering using methods in addition to "ward. D2", the patterns are generally similar though some differences are notable, particularly when comparing the results of microsatellites to any of the SNP datasets. The "single" method, which bases branch length between groups on the closest individual in each group, does not result in distinct populations using microsatellite data (Additional file 1: Fig. S1A), but results in the same clustering pattern as the "ward. D2" method for all SNPs (Additional file 1: Fig. S1B), putatively neutral SNPs (Additional file 1: Fig; S1C), and candidate loci (Additional file 1: Fig. S1D). The "complete" method, which bases branch length between groups on the most distant individuals, shows Cimarron, Crawford, and San Miguel individuals nested between groups of Gunnison Basin individuals while Dove Creek and Piñon Mesa are distinct when using microsatellites (Additional file 1: Fig. S2A), but results in nearly the same clustering pattern as with "ward. D2" when using all SNPs (Additional file 1: Fig. S2B), putatively neutral SNPs (Additional file 1: Fig. S2C) and candidate adaptive loci (Additional file 1: Fig. S2D), though a single San Miguel individual clusters with Cimarron using all SNPs and putatively neutral SNPs (Additional file 1: Fig. S2B and S2C).

\section{Discussion}

In general, we found that measures of diversity and differentiation generated from microsatellite and SNP data were typically in agreement in ranking of population 
estimates, although magnitudes of estimates were quite different. Metrics of differentiation, however, had consistently higher correlation than most metrics of diversity. Our results also confirmed that increased numbers of SNP loci can dramatically reduce the confidence intervals for mean estimates, increasing precision, although this was not true for all differentiation measures. We also demonstrated that clustering of individuals for the purpose of identifying evolutionarily or demographically distinct units can be variable depending on clustering method used and marker type.

\section{Genetic diversity}

Of the four diversity metrics evaluated here, $H_{\mathrm{E}}, F_{\mathrm{IS}}$, and $A_{\mathrm{R}}$ were the metrics with the highest correlation between microsatellites and SNPs (see Fig. 2). $H_{\mathrm{O}}$, however, showed relatively low correlation across marker types. Several previous studies with variable numbers of markers, sample sizes, and SNP discovery approaches generally agree with our correlation of diversity metrics across marker types, though positive relationships were sometimes moderate $[43,45,51,58,59,64]$. None of these studies report $H_{\mathrm{O}}$, and so there was no comparison for our relatively low correlation across marker types for this metric. Still, some argue higher correlation may be influenced by the number of SNPs [43], or whether loci represent a high proportion of the genome-wide polymorphism [74, 75]; two aspects of SNP datasets that will vary by study and may play a role in our observed correlations. Importantly, similar to findings by Fischer et al. [59], the high variance in microsatellite data for all diversity metrics resulted in almost no significant difference between populations; differences that were detected with SNPs. Though we, like others, show high correlation among marker types, the increased precision in estimates allow distinction of populations when using SNP data. For general monitoring of changes in diversity for conservation or management of a species, either marker type would prove useful. This was not necessarily true for $F_{\mathrm{IS}}$, where generally high correlation was observed, though ranking was not as consistent, and SNPs failed to detect the indication of inbreeding that was apparent with microsatellites (i.e., $F_{\mathrm{IS}}>0$; Fig. 1 \& Table S1). It is worth restating that samples were originally selected for the SNP data based on relatedness values estimated with the microsatellite data. Logically, selecting minimally related individuals could result in the SNP data producing $F_{\text {IS }}$ estimates consistent with more outbreeding than the original full microsatellite dataset. However, when we compared diversity metrics from a reduced microsatellite dataset including only the individuals used in the SNP dataset, we find no significant differences for any diversity metric according to the confidence intervals (Table $\mathrm{S} 1)$. However, the mean $\mathrm{F}_{\mathrm{IS}}$ estimates for the reduced microsatellite dataset would suggest a change in the sign of the estimate (i.e., either from inbreeding to outbreeding or outbreeding to inbreeding) for three populations. SNPs, however, would have an obvious advantage if conservation actions required an understanding of the relative levels or ranking of most measures of genetic diversity.

\section{Genetic differentiation}

In general agreement with multiple studies $[21,45,58-$ 60,64 ] all metrics of differentiation showed high correlation between microsatellites and SNP datasets, with correlation coefficients greater than 0.90 in all tests (Fig. 4) and significant Mantel correlations (Mantel $r>0.9$, $p \leq 0.05$ for all comparisons). Some argue reliance on a single measure of differentiation for conservation purposes risks inaccurate characterization of populations [76-78]. Our findings, however, echo other empirical examples where different metrics result in the same inference $[11,60]$, but only when ranking populations (Wilcoxon paired signed-rank test $p \leq 0.05$ in all comparisons). Different metrics of population differentiation showed a consistent pattern of which populations were most similar, though the magnitude of a metric was sometimes very different. If the magnitude of the differentiation metric is of conservation relevance, then the marker types are not equivalent.

The appropriateness of a differentiation metric in conservation can be further impacted by additional differences in marker types. The different metrics measure different things. $D_{\text {Jost }}$ is considered a relative degree of allelic differentiation, while $F_{\mathrm{ST}}$ and $G_{\mathrm{ST}}$ are fixation indices [78]. Similar to some previous studies, we found $D_{\text {Iost }}$ tended to produce values higher in magnitude with microsatellites than with SNPs [64]. Each microsatellite locus will always have higher per locus allelic diversity than biallelic SNP loci, and therefore result in higher magnitude estimates of $D_{\text {Jost }}[78,79]$. We also found higher $G_{\text {ST }}$ estimates with microsatellites (Fig. 3b \& Table S2), although the magnitude of difference between the values calculated from different marker types was not as dramatic as that with $D_{\text {Jost }}$ (Fig. 3c \& Table S2). $G_{\mathrm{ST}}$ depends on heterozygosity, so the higher theoretical maximum heterozygosity for microsatellite loci $\left(H_{\mathrm{E}}=1\right)$, versus the theoretical maximum heterozygosity for SNP loci $\left(H_{\mathrm{E}}=0.5\right)$, will also result in higher magnitudes of $G_{\text {ST }}$ when calculated from microsatellite data. Importantly, $F_{\mathrm{ST}}$ has proven to be more robust to per locus allelic diversity and heterozygosity (though see $[59,60]$ ). From a conservation perspective, $F_{\mathrm{ST}}$ may prove most useful in the transition from microsatellite loci to SNPs for genetic monitoring because of the observed consistency across marker types. However, $D_{\text {Jost }}$ may actually be the more relevant conservation metric if 
comparing relative degrees of differentiation or identifying isolated groups because the level of differentiation takes into account allelic identity and not just population level fixation [78]. Fixation indices will indicate two populations fixed for the same allele are distinct because both populations lack diversity at a locus while allelic differentiation metrics will not because the identity of the fixed allele is the same and therefore populations are not different at that locus.

The three differentiation metrics evaluated here also have different sensitivities to the underlying mutation rate generating each type of marker with $F_{\mathrm{ST}}$ proving more robust $[78,80]$. In addition to impacts from mutation rate on different metrics, migration rate and population size are also important to consider. Whitlock [80] demonstrated that for low mutation rates, approximately that of SNPs (10E-9), and low migration rates among a small number of populations, measures of differentiation as measured by $D_{\text {Iost }}$ will be much smaller in magnitude, and to a lesser degree, so will $G_{\mathrm{ST}}$. Relatively low levels of mutation, migration, and small populations typically correspond to lower allelic diversity. Gunnison sagegrouse is composed of seven isolated populations, with very low migration rates among populations, though not as low as SNP mutation rates. Our comparison of $F_{\mathrm{ST}}$ values across marker types demonstrates relatively consistent agreement between both magnitude and ranking of pair-wise comparisons (Fig. 3a). As predicted, $D_{\text {Jost }}$ and $G_{\mathrm{ST}}$ consistently rank comparisons across marker type, though the magnitude of metrics were lower for SNPs than microsatellites; much lower in the case of $D_{\text {Iost }}$ (Fig. $3 \mathrm{~b}$ and c). Overall, our results empirically demonstrate the predicted impact population configurations can have on measures of differentiation.

Both marker types suffer from additional characteristics that can influence estimates of differentiation. In addition to the influence of heterozygosity and allelic diversity on measures of differentiation, there is a trade-off between the number of loci and the per locus information content. More SNP loci will be required to obtain the same resolution in differentiation metrics from fewer microsatellite loci, because the number of alleles per locus can impact the ability to detect reproductively isolated groups. If a locus only has two alleles, as is typical with SNP loci, the chances of populations differing in allele frequencies at high enough levels to detect isolation is lower. Conversely, if a locus has multiple alleles shared among populations, the differences in allele frequencies are more likely to be detected, therefore showing the level of reproductive isolation. Many studies have provided suggestions on the number of SNPs required to obtain resolution in differentiation comparable to that obtained with microsatellites, ranging from two to 11 times more SNP loci $[25,57,81]$. However, more recent work has indicated fewer SNPs than previously suggested can be sufficient $[47,58,60,82]$. We did not explicitly evaluate the number of SNP loci required to obtain estimates with the precision of microsatellites, though we do demonstrate that 14,091 biallelic putatively neutral SNPs results in comparable estimates to 22 microsatellites with three to 18 alleles per locus. Our study likely reflects a typical number of SNPs which would be obtained with a RAD-Seq protocol, the most commonly used approach for wildlife species. We therefore, demonstrate RAD-Seq generated SNP genotypes can produce comparable differentiation estimates to those obtained with microsatellites.

We do not, however, demonstrate a dramatic reduction in confidence intervals around those measures of differentiation (Fig. 3), as has been predicted. However, in pair-wise comparisons of differentiation, the small sample size of one of the populations is known to impact the confidence intervals [83]. In our data, we see this trend particularly for $F_{\mathrm{ST}}$ and with comparisons involving our smallest population represented by the fewest samples, Cimarron (Fig. 2). In species of conservation concern variable population sizes are often unavoidable, and by increasing the number of loci sampled (>1000 SNPs) robust estimates of differentiation can still be obtained [83].

\section{Clustering}

Contrary to our findings for differentiation, the clustering analyses showed an increase in precision with SNP data that is consistent with previous studies $[45,61,64]$. We used multiple methods to cluster individuals (dendrograms and DAPC) all of which showed general agreement of clustering by population of origin (Figs. 5b, c, and $d, 6 b$, and $c$ ). The SNP data, however, resulted in tighter groups of individuals (Figs. $5 \mathrm{c}$ and $6 \mathrm{c}$ ) relative to the somewhat loose clusters of individuals with microsatellite data (Figs. 5a and 6a). The number of individuals sampled varied by marker type in our study (256 in the microsatellite dataset versus 60 in the SNP datasets), which could potentially contribute to the lower resolution in clustering analyses when compared to the SNP data. However, when we looked at clustering of microsatellite data using only the 60 individuals included in the SNP data, the patterns of clustering remain the same (Additional file 1: Fig. S3 and S4), similar to what Lemopoulos et al. [45] found.

The potential impact of conservation actions on a species local fitness and how that relates to adaptive divergence is important to consider [84], especially for a species with geographically distinct and declining populations. Identifying candidate adaptive loci can provide insight into the potential adaptive divergence among populations and the potential for local adaption. We also 
compared clustering of individuals by previously identified candidate adaptive loci [65], an objective that cannot be accomplished with microsatellite loci (i.e., neutral loci) alone. We found evidence of adaptive divergence in two or three populations (Figs. 5d, 6d, S1D, and S2D), depending on the method used for clustering. Though the small populations and small sample sizes could be causing fixation of alleles due to strong drift, the approaches used to identify candidate adaptive loci generally control for demography (e.g., BayPass and partial RDA; see Zimmerman et al. [65]).

Comparing the clustering of individuals with all SNP loci (Figs. 5b and 6b) to clustering including only putatively neutral (Figs. 5c and 6c) or candidate adaptive (Figs. 5d and 6d) loci, we see that neutral genetic processes in Gunnison sage-grouse may be stronger than adaptive divergence. Evidence of adaptive divergence corresponded to approximately 6\% (942 SNPs) of the sampled genome. Neutral and adaptive variation are both important to consider for designation as an ESU or conservation unit $[37,40]$. However, the ratio of neutral versus adaptive loci undoubtedly influences identification of distinct units. In addition to considering the marker type, it could be important to identify what proportion of the genome must hold the signal for adaptive divergence for formal designation. The term functionally significant unit (FSU) was recently suggested to describe conservation units based on ecologically important genes [85]. More recently, a single ecologically important gene was used to propose conservation units for salmon [12]. Most genes underlying phenotypes are quantitative in nature with only preliminary ecological links, and so single gene definitions of conservation units will be rare at best [86]. Further, the focus on identifying conservation units based on potential adaptive divergence may result in unintended consequences such as reduced effort to conserve or restore habitat [86], overlooking the role vicariance events may play in adaptation [87], or a failure to acknowledge traits that are adaptive in a given environment presently may not be locally adapted in future environments. Importantly, questions of local adaptation and evolutionary independence cannot be considered with microsatellite loci, or any neutral loci alone. Attempts to identify distinct units with genetic data should focus on using SNP data, or a combination of neutral (microsatellite or SNP) in combination with known ecologically important functional regions.

\section{Conclusions}

We demonstrated that RAD-Seq generated SNPs from a non-model organism are generally comparable to microsatellites for measuring population genetic parameters, in agreement with some previous studies $[45,51,64]$. The rapid progression away from use of microsatellites and toward use of SNP data in conservation and management applications highlights the importance of these types of comparisons and calls into question the future usefulness of microsatellite data. As we, and others, have shown, the same general inference can typically be drawn about population-level genetic differentiation and diversity, irrespective of marker type. However, we showed that SNPs had three main advantages over microsatellites. First, the much smaller confidence intervals around diversity measures allowed distinctions between populations to be made with SNP data. From a conservation perspective, all populations of Gunnison sage-grouse would have been considered equally diverse using microsatellite loci, while there were clear differences in relative diversity with SNP data. Second, clustering methods showed a dramatic increase in the power to separate individuals into distinct groups. Microsatellite data failed to clearly separate individuals into populations in nearly all instances; populations that were clearly differentiated with SNP data. Third, SNP data allows consideration of local adaptation.

We also further demonstrated the impact of marker choice on differentiation metrics-different marker types resulted in very different magnitudes. This finding exemplifies the dangers of using thresholds for differentiation and diversity metrics for conservation objectives. If the magnitude of the value is not of importance, all metrics except $H_{\mathrm{O}}$ and $F_{\mathrm{IS}}$ were able to consistently rank populations or population pairs across marker types in our study. While we found clear advantages for use of SNPs in population genetics, there remain some limitations at present. Primarily, generation of SNP datasets requires relatively large quantities of high quality DNA, which is often difficult to obtain from species of conservation concern. However, investing in the development of a SNP panel or using a target capture approach can facilitate use of low quality samples [88]. On the other hand, microsatellites are extremely useful with low quality samples, are becoming less costly and time consuming to develop (e.g., Castoe et al. [89]), and have already been widely used in conservation and management programs for long-term monitoring of many species. Although general usefulness of microsatellites in the future is uncertain, microsatellite loci will likely remain useful for relatedness, parentage analysis, and genetic mark-recapture due to their highly polymorphic nature and mixed performance with SNP data $[46,47,49,53,54,88]$.

\section{Methods \\ Data}

\section{Microsatellite genotypes}

Blood samples were collected near breeding grounds within six of the populations as part of a 2005 study [69]. The dataset we use here is composed of 254 
individuals from these previously collected samples that were genotyped at a larger set of microsatellite loci for a 2019 study [73]. Sample size varied by population: Cimarron $=4$, Crawford $=21$, Dove Creek $=43$, Gunnison Basin $=116$, Piñon Mesa $=19$, San Miguel $=51$. Populations are named after nearby Colorado towns with 2 exceptions, Piñon Mesa is located west of Grand Junction and San Miguel is south of Norwood. We amplified 22 grouse-specific microsatellite loci using the Polymerase Chain Reaction (PCR) and with the components and concentrations described in Oyler-McCance and Fike [90] with thermal profiles and annealing temperatures as originally published. The microsatellite primers used included: MSP11, MSP18, reSGCA5, reSGCA11, SG21, SG23, SG24, SG28, SG29, SG30, SG31, SG33, SG36, SG38, SG39, SGCTAT1, SGMS06.4, SGMS06.8, TTT3, TUT3, TUT4, and WYBG6 [91-96]. See Zimmerman et al. [73] for details on DNA extraction and genotyping. The final microsatellite dataset was composed of 22 relatively polymorphic sampled loci, for a total of 254 individuals, with variable representation by geographic population.

\section{Single nucleotide polymorphism (SNP) genotypes}

From the same 254 previously collected blood samples that were genotyped at microsatellite loci, a subset were previously chosen for RAD-Seq [65] based on two criteria: population of origin and relatedness. The goal was to obtain an equal number of minimally related individuals from each population. The exception to these requirements was the Cimarron population, which only had four samples; consequently all Cimarron samples were included. These criteria for sample selection were necessary because of limited available funding and high enough quality samples. See Zimmerman et al. [65] for details on RAD-Seq library preparation and bioinformatics. The complete SNP dataset was composed of 15,033 loci across 35 "pseudo-chromosomes" (chromosome scaffolds inferred from synteny with chicken) for 60 individuals (Cimarron $=4$, Crawford $=12$, Dove Creek $=$ 12, Gunnison Basin $=12$, Pinon Mesa $=10$, San Miguel = 10). A putatively adaptive SNP dataset composed of all 942 loci that were previously identified as potentially under selection in outlier locus analyses and genotypeenvironment association analyses was also created. Methods used to identify putatively adaptive loci included BayPass [97], pcadapt [98], and a redundancy analysis as described in [99]. Environmental covariates used in the genotype-environment association included average spring precipitation, average fall precipitation, spring maximum temperature, winter maximum vapor pressure deficit, compound topographic index (a proxy for soil moisture), green-up rate (a measure of the progression of the growing season), big sagebrush cover, and a dryness index (see Zimmerman et al. [65] for details on loci under selection). A putatively neutral SNP dataset was created by excluding all putatively adaptive loci. The final putatively neutral SNP dataset included 14,091 biallelic loci across 34 pseudo-chromosomes, for 60 individuals with relatively equal representation from each geographic population.

\section{Analysis of genetic diversity}

For each putatively neutral dataset, we estimated observed heterozygosity $\left(H_{\mathrm{O}}\right)$, expected heterozygosity $\left(H_{\mathrm{E}}\right)$, allelic richness per locus $\left(A_{\mathrm{R}}\right)$, and inbreeding coefficient $\left(F_{\mathrm{IS}}\right)$ using the 'diveRsity' [100] package in $\mathrm{R}$ [101]. Diversity metrics were estimated for each locus based on 1000 bootstraps and reported as a mean and 95\% confidence intervals constructed from the standard deviation across all loci. Mean allelic richness per locus was also estimated with rarefaction for comparison (results included in Additional file 1: Table S1). Diversity metrics were calculated for both datasets and used to compare estimates from microsatellite and putatively neutral SNPs. Pearson and Spearman rank correlation coefficients were estimated to evaluate congruence for all paired metrics. Wilcoxon paired signed-rank test in the R package 'MASS' [102] was used to evaluate the consistency of ranked values among datasets.

\section{Analysis of genetic differentiation}

For genetic differentiation we compared analysis results from microsatellites, all SNPs, and putatively neutral SNPs. We used the 'diveRsity' package in $\mathrm{R}$ to calculate $F_{\mathrm{ST}}$ [103] with confidence intervals based on 1000 bootstraps. Because there is concern about comparing pairwise $F_{\mathrm{ST}}$ values when using loci with variable levels of heterozygosity, we also calculated pair-wise $G_{\mathrm{ST}}$ [104] and $D_{\text {Jost }}[79]$ with confidence intervals based on 1000 bootstraps. $D_{\text {Jost }}$ differs from both $F_{\mathrm{ST}}$ and $G_{\mathrm{ST}}$ in that it is a measure of the fraction of allelic variation among populations and is not constrained by the expected level of heterozygosity within the subpopulation [79]. Significance of correlation between pair-wise differentiation measures for each dataset was evaluated with the Mantel $p$-value as calculated with the 'vegan' R package [105].

\section{Analysis of clustering}

We compared the identification of distinct units using microsatellites, all SNPs, putatively neutral SNPs, and putatively adaptive SNPs. First, we performed discriminnant analysis of principal components (DAPC) with microsatellites, putatively neutral SNPs, all SNPs, and candidate adaptive loci with the 'adegenet' package in $\mathrm{R}$ [106]. DAPC summarizes genotypes in principal components (PC) that are then used to construct linear functions that simultaneously maximize among-cluster 
variation and minimize within cluster variation. We used the $K$-means clustering algorithm and identified the number of genetic clusters based on the Bayesian Information Criterion (BIC). We retained all of the PCs, ran the algorithm for 100,000 iterations, and used 10 starting centroids per run. The number of genetic clusters $(K)$ with the lowest BIC was selected, as recommended by Jombart et al. [107]. After we identified optimal $K$ for each dataset, we used the a-score method to identify the optimal number of PCs to retain in DAPC while constructing linear functions to describe genetic differentiation among $K$ groups. Second, we created dendrograms from an individual-based genetic distance matrix calculated as the proportion of differing nucleotide sites [108], excluding missing data in pair-wise estimations, with 1000 bootstraps for each dataset. We used the hierarchical clustering algorithm hclust in $\mathrm{R}$ and the "ward. D2" method [109]. The "ward. D2" method minimizes the total within cluster variance and minimizes information loss associated with each cluster. For comparison of hierarchical clustering methods we also included dendrograms created with a more conservative method tending to form loose groups, sometimes prematurely ("single" method; Additional file 1: Fig. S1) and a more relaxed method tending to form tighter and smaller groups ("complete" method; Additional file 1: Fig. S2). For comparison, results for clustering analyses with a reduced microsatellite dataset using only individuals in the SNP dataset are included in the supplemental materials (Additional file 1: Fig. S3 and Fig. S4).

\section{Supplementary information}

Supplementary information accompanies this paper at https://doi.org/10. 1186/s12864-020-06783-9.

Additional file 1: Table S1. Diversity statistics. Table S2. Differentiation statistics. Fig. S1. Dendrograms created using the "single" (based on closest pair) method. Fig. S2. Dendrograms created using the "complete" (based on furthest pair) method. Fig. S3. Dendrograms created using microsatellite loci from the 60 individuals included in the SNP dataset. Fig. S4. Discriminant analysis of principle components (DAPC) for microsatellite from the 60 individuals sampled for SNPs.

\section{Abbreviations}

BIC: Bayesian information criterion; CM: Cimarron; CR: Crawford; DAPC: Discriminant analysis of principal components; DC: Dove Creek; DNA: Deoxyribonucleic acid; ESA: Endangered species act; ESU: Evolutionarily significant unit; FSU: Functionally significant unit; GB: Gunnison Basin; MSAT: Microsatellite; PC: Principal component; PCR: Polymerase chain reaction; PM: Piñon Mesa; SM: San Miguel Basin; SNP: Single nucleotide polymorphism

\section{Acknowledgements}

The data used in this manuscript were collected by many entities for previous projects. We would like to acknowledge the groups that provided the original samples explicitly: Colorado Parks and Wildlife (especially Dr. Anthony D. Apa), the National Park Service, the Bureau of Land Management, the U.S. Forest Service, volunteers from Western Colorado University, the U.S. Geological Survey, and Colorado State University. We would also like to thank those who helped in the review process: Drs. M.P. Miller, W.C. Funk,
M.B. Hooten, and 3 anonymous reviwers. Any use of trade, firm, or product names is for descriptive purposes only and does not imply en- dorsement by the U.S. Government.

\section{Authors' contributions}

SJZ, SJOM and CLA designed the study. SJZ performed analyses. All authors contributed to the manuscript. All authors have read and approved the manuscript.

\section{Funding}

Not applicable.

\section{Availability of data and materials}

The microsatellite dataset is available in the U.S. Geological Survey Science Base repository, https://doi.org/10.5066/P920WO0Q. Genomic sequencing data for this study were deposited in GenBank (biosample accession numbers: SAMN10844489-SAMN10844548) and SNP genotypes for this study were deposited in the U.S. Geological Survey ScienceBase, https://doi.org/10. 5066/P94ET592

\section{Ethics approval and consent to participate}

Not applicable. Samples used here were obtained for previously published studies from birds that had been either killed by hunters or trapped under Colorado Division of Wildlife IACUC protocols $[69,73]$.

\section{Consent for publication}

Not applicable.

\section{Competing interests}

The authors declare that they have no competing interests.

Received: 27 November 2019 Accepted: 14 May 2020

Published online: 01 June 2020

\section{References}

1. Desalle R, Amato G. The expansion of conservation genetics. Nat Rev Genet. 2004;5:702-12..

2. Paetkau D, Calvert W, Stirling I, Strobeck C. Microsatellite analysis of population structure in Canadian polar bears. Mol Ecol. 1995;4:347-54

3. Broders HG, Mahoney SP, Montevecchi WA, Davidson WS. Population genetic structure and the effect of founder events on the genetic variability of moose, Alces alces, in Canada. Mol Ecol. 1999:8:1309-15.

4. Hauser L, Adcock GJ, Smith PJ, Bernal Ramirez JH, Carvalho GR. Loss of microsatellite diversity and low effective population size in an overexploited population of New Zealand snapper (Pagrus auratus). Proc Natl Acad Sci. 2002;99:11742-7.

5. Noël S, Ouellet M, Galois P, Lapointe F-J. Impact of urban fragmentation on the genetic structure of the eastern red-backed salamander. Conserv Genet. 2007:8:599-606.

6. de Wit P, Palumbi SR. Transcriptome-wide polymorphisms of red abalone (Haliotis rufescens) reveal patterns of gene flow and local adaptation. Mol Ecol. 2013;22:2884-97.

7. Lawson LP, Petren K. The adaptive genomic landscape of beak morphology in Darwin's finches. Mol Ecol. 2015;2017:4978-89.

8. Brousseau L, Fine PVA, Dreyer E, Vendramin GG, Scotti I. Genomics of microgeographic adaptation in the hyperdominant Amazonian tree Eperua falcata Aubl. (Fabaceae). bioRxiv. 2018:312843.

9. Holycross AT, Douglas ME. Geographic isolation, genetic divergence, and ecological non-exchangeability define ESUs in a threatened sky-island rattlesnake. Biol Conserv. 2007;134:142-54.

10. Quintela M, Berlin S, Wang B, Höglund J. Genetic diversity and differentiation among Lagopus lagopus populations in Scandinavia and Scotland: evolutionary significant units confirmed by SNP markers. Mol Ecol. 2010;19:2380-93.

11. Funk WC, Lovich RE, Hohenlohe PA, Hofman CA, Morrison SA, Sillett TS, et al. Adaptive divergence despite strong genetic drift: genomic analysis of the evoutionary mechanisms causing genetic differentiation in the island fox (Uryocyon littoralis). Mol Ecol. 2016;25:2176-94.

12. Prince DJ, O'Rourke SM, Thompson TQ, Ali OA, Lyman HS, Saglam IK, et al. The evolutionary basis of premature migration in Pacific salmon highlights 
the utility of genomics for informing conservation. Sci Adv. 2017;3: e1603198.

13. Tautz D. Hypervariability of simple sequences as a general source for polymorphic DNA markers. Nucleic Acids Res. 1980;8:4321-6.

14. Miesfeld R, Krystal M, Amheim N. A member of a new repeated sequence family which is conserved throughout eucaryotic evolution is found between the human $\delta$ and $\beta$ globin genes. Nucleic Acids Res. 1981;9:5931-48.

15. Baumung BR, Simianer H, Hoffmann I. Genetic diversity studies in farm animals - a survey. J Anim Breed Genet. 2004;121:361-73.

16. Schlötterer C. Opinion: the evolution of molecular markers - just a matter of fashion? Nat Rev Genet. 2004:5:63-9.

17. Hansson B, Westerberg L. On the correlation between heterozygosity and fitness in natural populations. Mol Ecol. 2002;11:2467-74.

18. LaHood ES, Moran P, Olsen J, Stewart Grant W, Park LK. Microsatellite allele ladders in two species of Pacific salmon: preparation and field-test results. Mol Ecol Notes. 2002;2:187-90.

19. Davison A, Chiba S. Laboratory temperature variation is a previously unrecognized source of genotyping error during capillary electrophoresis. Mol Ecol Notes. 2003:3:321-3.

20. Amos W, Hoffman Jl, Frodsham A, Zhang L, Best S, Hill AVS. Automated binning of microsatellite alleles: problems and solutions. Mol Ecol Notes. 2007;7:10-4.

21. Morin PA, Martien KK, Taylor BL. Assessing statistical power of SNPs for population structure and conservation studies. Mol Ecol Resour. 2009;9:66-73.

22. Kim KS, Ratcliffe ST, French BW, Liu L, Sappington TW. Utility of EST-derived SSRs as population genetics markers in a beetle. J Hered. 2008;99:112-24.

23. Vignal A, Milan D, SanCristobal M, Eggen A. Exploring the assumptions underlying genetic variation in host. Genet Sel Evol. 2002;34:275-305.

24. Landegren $\mathrm{U}$, Nilsson $\mathrm{M}$, Kwok P. Reading bits of genetic information: methods for single-nucleotide polymorphism analysis. Genome Res. 1998;8: 769-76.

25. Morin PA, Luikart G, Wayne RK. SNPs in ecology, evolution and conservation. Trends Ecol Evol. 2004;19:208-19.

26. Xing C, Schumacher FR, Xing G, Lu Q, Wang T, Elston RC. Comparison of microsatellites, single-nucleotide polymorphisms (SNPs) and composite markers derived from SNPs in linkage analysis. BMC Genet. 2005;6 SUPPL.1:S29.

27. Brumfield RT, Beerli P, Nickerson DA, Edwards SV. The utility of single nucleotide polymorphisms in inferences of population history. Trends Ecol Evol. 2003;18:249-56.

28. Väli Ü, Einarsson A, Waits $L$, Ellegren $H$. To what extent do microsatellite markers reflect genome-wide genetic diversity in natural populations? Mo Ecol. 2008;17:3808-17.

29. Baird NA, Etter PD, Atwood TS, Currey MC, Shiver AL, Lewis ZA, et al. Rapid SNP discovery and genetic mapping using sequenced RAD markers. PLoS One. 2008:3:e3376.

30. Davey JW, Hohenlohe PA, Etter PD, Boone JQ, Catchen JM, Blaxter ML. Genome-wide genetic marker discovery and genotyping using nextgeneration sequencing. Nat Rev Genet. 2011;12:499-510.

31. Krawczak M. Informativity assessment for biallelic single nucleotide polymorphisms. Electrophoresis. 1999;20:1676-81.

32. Nielsen R. Estimation of population parameters and recombination rates from single nucleotide polymorphisms. Genetics. 2000;154:931-42.

33. Allendorf FW, Hohenlohe PA, Luikart G. Genomics and the future of conservation genetics. Nat Rev Genet. 2010;11:697-709.

34. Bradbury IR, Hamilton LC, Dempson B, Robertson MJ, Bourret V, Bernatchez $L$, et al. Transatlantic secondary contact in Atlantic Salmon, comparing microsatellites, a single nucleotide polymorphism array and restriction-site associated DNA sequencing for the resolution of complex spatial structure. Mol Ecol. 2015;24:5130-44

35. Allendorf FW, Luikart G, Aitken SN. Conservation and the genetics of populations. 2nd ed. New York: Wiley-Blackwell; 2013.

36. Oyler-McCance SJ, Oh KP, Langin KM, Aldridge CL. A field ornithologist's guide to genomics: practical considerations for ecology and conservation. Auk. 2016;133:626-48.

37. Crandall KA, Bininda-Emonds ORP, Mace GM, Wayne RK. Considering evolutionary processes in conservation biology. Trends Ecol Evol. 2000;15: 290-5.

38. Fraser DJ, Bernatchez L. Adaptive evolutionary conservation: towards a unified concept for defining conservation units. Mol Ecol. 2001;10:2741-52.

39. Palsbøll PJ, Bérubé M, Allendorf FW. Identification of management units using population genetic data. Trends Ecol Evol. 2007;22:11-6.
40. Funk WC, McKay JK, Hohenlohe PA, Allendorf FW. Harnessing genomics for delineating conservation units. Trends Ecol Evol. 2012;27:489-96.

41. Robertson JM, Langin KM, Sillett TS, Morrison SA, Ghalambor CK, Funk WC. Identifying evolutionarily significant units and prioritizing populations for management on islands. Monogr West North Am Nat. 2014;7:397-411.

42. Waples RS. Evolutionarily significant units and the conservation of biological diversity under the endangered species act. Am Fish Soc Symp. 1995;17:8-27.

43. Miller JM, Malenfant RM, David P, Davis CS, Poissant J, Hogg JT, et al. Estimating genome-wide heterozygosity: effects of demographic history and marker type. Heredity (Edinb). 2014;112:240-7.

44. Kaiser SA, Taylor SA, Chen N, Sillett TS, Bondra ER, Webster MS. A comparative assessment of SNP and microsatellite markers for assigning parentage in a socially monogamous bird. Mol Ecol Resour. 2017;17:183-93.

45. Lemopoulos A, Prokkola JM, Uusi-Heikkilä S, Vasemägi A, Huusko A, Hyvärinen P, et al. Comparing RADseq and microsatellites for estimating genetic diversity and relatedness - implications for brown trout conservation. Ecol Evol. 2019;9:2106-20.

46. Hamblin MT, Warburton ML, Buckler ES. Empirical comparison of simple sequence repeats and single nucleotide polymorphisms in assessment of maize diversity and relatedness. PLoS One. 2007;2:e1367.

47. Narum SR, Banks MA, Beacham TD, Bellinger MR, Campbell MR, Dekoning J, et al. Differentiating salmon populations at broad and fine geographical scales with microsatellites and single nucleotide polymorphisms. Mol Ecol. 2008;17:3464-77.

48. Hauser L, Baird M, Hilborn R, Seeb LW, Seeb JE. An empirical comparison of SNPs and microsatellites for parentage and kinship assignment in a wild sockeye salmon (Oncorhynchus nerka) population. Mol Ecol Resour. 2011; 11(SUPPL. 1):150-61

49. Weinman $L R$, Solomon JW, Rubenstein DR. A comparison of single nucleotide polymorphism and microsatellite markers for analysis of parentage and kinship in a cooperatively breeding bird. Mol Ecol Resour. 2015;15:502-11.

50. Mesak F, Tatarenkov A, Earley RL, Avise JC. Hundreds of SNPs vs. dozens of SSRs: Which dataset better characterizes natural clonal lineages in a selffertilizing fish? Front Ecol Evol. 2014;2:74.

51. Roques S, Chancerel E, Boury C, Pierre M, Acolas M. From microsatellites to single nucleotide polymorphisms for the genetic monitoring of a critically endangered sturgeon. Ecol Evol. 2019; in press.

52. Tokarska M, Marshall T, Kowalczyk R, Wójcik JM, Pertoldi C, Kristensen TN, et al. Effectiveness of microsatellite and SNP markers for parentage and identity analysis in species with low genetic diversity: the case of European bison. Heredity (Edinb). 2009;103:326-32.

53. Fernández ME, Goszczynski DE, Lirón JP, Villegas-Castagnasso EE, Carino MH, Ripoli MV, et al. Comparison of the effectiveness of microsatellites and SNP panels for genetic identification, traceability and assessment of parentage in an inbred Angus herd. Genet Mol Biol. 2013;36:185-91.

54. Herráez DL, Schäfer H, Mosner J, Fries HR, Wink M. Comparison of microsatellite and single nucleotide polymorphism markers for the genetic analysis of a Galloway cattle population. Zeitschrift fur Naturforsch - Sect C J Biosci. 2005;60:637-43.

55. Ball AD, Stapley J, Dawson DA, Birkhead TR, Burke T, Slate J. A comparison of SNPs and microsatellites as linkage mapping markers: lessons from the zebra finch (Taeniopygia guttata). BMC Genomics. 2010;11:218.

56. Schaid DJ, Guenther JC, Christensen GB, Hebbring S, Rosenow C, Hilker CA, et al. Comparison of microsatellites versus single-nucleotide polymorphisms in a genome linkage screen for prostate cancer-susceptibility loci. Am J Hum Genet. 2004;75:948-65.

57. Van Inghelandt D, Melchinger AE, Lebreton C, Stich B. Population structure and genetic diversity in a commercial maize breeding program assessed with SSR and SNP markers. Theor Appl Genet. 2010;120:1289-99.

58. Ryynänen $\mathrm{HJ}$, Tonteri A, Vasemägi A, Primmer CR. A comparison of biallelic markers and microsatellites for the estimation of population and conservation genetic parameters in Atlantic salmon (Salmo salar). J Hered. 2007:98:692-704.

59. Fischer MC, Rellstab C, Leuzinger M, Roumet M, Gugerli F, Shimizu KK, et al. Estimating genomic diversity and population differentiation - an empirical comparison of microsatellite and SNP variation in Arabidopsis halleri. BMC Genomics. 2017:18:69.

60. Coates BS, Sumerford DV, Miller NJ, Kim KS, Sappington TW, Siegfried BD, et al. Comparative performance of single nucleotide polymorphism and microsatellite markers for population genetic analysis. J Hered. 2009;100:556-64. 
61. Morin PA, Archer Fl, Pease VL, Hancock-Hanser BL, Robertson KM, Huebinger RM, et al. An empirical comparison of SNPs and microsatellites for population structure, assignment, and demographic analyses of bowhead whale populations. Endanger Species Res. 2012;19:1-27.

62. Liu N, Chen L, Wang S, Oh C, Zhao H. Comparison of single-nucleotide polymorphisms and microsatellites in inference of population structure. BMC Genet. 2005;6 SUPPL.1:S26.

63. Pante E, Abdelkrim J, Viricel A, Gey D, France SC, Boisselier MC, et al. Use of RAD sequencing for delimiting species. Heredity (Edinb). 2015;114:450-9.

64. Langin KM, Aldridge CL, Fike JA, Cornman RS, Martin K, Wann GT, et al. Characterizing range-wide divergence in an alpine-endemic bird: a comparison of genetic and genomic approaches. Conserv Genet. 2018; 19:1471-85

65. Zimmerman SJ, Aldridge CL, Oh KP, Cornman RS, Oyler-McCance SJ. Signatures of adaptive divergence among populations of an avian species of conservation concern. Evol Appl. 2019;12:1661-77.

66. Schroeder MA, Aldridge CL, Apa AD, Bohne JR, Braun CE, Bunnell SD, et al. Distribution of sage-grouse in North America. Condor. 2004;106:363-76.

67. Braun CE, Oyler-McCance SJ, Nehring JA, Commons ML, Young JR, Potter KM. The historical distribution of Gunnison sage-grouse in Colorado. Wilson J Ornithol. 2014;126:207-17.

68. Gunnison sage-grouse Rangewide Steering Committee. Gunnison sage-grouse rangewide conservation plan. Denver: Colorado Division of Wildlife; 2005

69. Oyler-McCance SJ, St John J, Taylor SE, Apa AD, Quinn TW. Population genetics of Gunnison sage-grouse: implications for management. J Wild Manag. 2005;69:630-7.

70. United States Fish and Wildlife Service. Endangered and threatened wildlife and plants; threatened status for Gunnison sage-grouse. Federal Register. 2014;79:69192-310.

71. Nehring JA, Apa AD. Gunnison sage-grouse population augmentation to Poncha pass. Montrose County: Saguache County \& Sims Mesa; 2000.

72. Wright BR, Grueber CE, Lott MJ, Belov K, Johnson RN, Hogg CJ. Impact of reduced-representation sequencing protocols on detecting population structure in a threatened marsupial. Mol Biol Rep. 2019; in press.

73. Zimmerman SJ, Aldridge CL, Apa AD, Oyler-McCance SJ. Evaluation of genetic change from translocation among Gunnison sage-grouse (Centrocercus minimus) populations. Condor. 2019;121:1-14.

74. Chakraborty R. The distribution of the number of heterozygous loci in an individual in natural populations. Genetics. 1981;98:461-6.

75. DeWoody YD, DeWoody JA. On the estimation of genome-wide heterozygosity using molecular markers. J Hered. 2005;96:85-8.

76. Meirmans PG, Hedrick PW. Assessing population structure: $F_{S T}$ and related measures. Mol Ecol Resour. 2011;11:5-18.

77. Verity $R$, Nichols RA. What is genetic differentiation, and how should we measure it - GST, D, neither or both? Mol Ecol. 2014;23:4216-25.

78. Jost L, Archer F, Flanagan S, Gaggiotti O, Hoban S, Latch E. Differentiation measures for conservation genetics. Evol Appl. 2018;11:1139-48.

79. Jost L. GST and its relatives do not measure differentiation. Mol Ecol. 2008; 17:4015-26.

80. Whitlock MC. GST and D do not replace F FT. Mol Ecol. 2011;20:1083-91.

81. Kalinowski ST. How many alleles per locus should be used to estimate genetic distances? Heredity (Edinb). 2002;88:62-5.

82. Morin PA, Manaster C, Mesnick SL, Holland R. Normalization and binning of historical and multi-source microsatellite data: overcoming the problems of allele size shift with allelogram. Mol Ecol Resour. 2009;9:1451-5.

83. Willing E-M, Dreyer C, van Oosterhout C. Estimates of genetic differentiation measured by $F_{S T}$ do not necessarily require large sample sizes when using many SNP markers. PLoS One. 2012;7:1-7.

84. Edmands S. Between a rock and a hard place: evaluating the relative risks of inbreeding and outbreeding for conservation and management. Mol Ecol. 2007;16:463-75.

85. van Tienderen PH, de Haan AA, van der Linden CG, Vosman B. Biodiversity assessment using markers for ecologically important traits. Trends Ecol Evol. 2002;17:577-82.

86. Kardos M, Shafer ABA. The peril of gene-targeted conservation. Trends Ecol Evol. 2018;33:827-39.

87. Dimmick WW, Ghedotti MJ, Grose MJ, Maglia AM, Meinhardt DJ, Pennock DS. The importance of systematic biology in defining units of conservation. Conserv Biol. 1999;13:653-60.

88. Oyler-McCance SJ, Oh KP, Zimmerman SJ, Aldridge CL. The transformative impact of genomics on sage-grouse conservation and management. In:
Hohenlohe PA, Rajora OP, editors. Population Genomics: Wildlife. Cham: Springer; 2020.

89. Castoe TA, Poole AW, de Koning APJ, Jones KL, Tomback DF, OylerMcCance SJ, et al. Rapid microsatellite identification from Illumina pairedend genomic sequencing in two birds and a snake. PLoS One. 2012;7: e30953.

90. Oyler-McCance SJ, Fike JA. Characterization of small microsatellite loci isolated in endangered Indiana bat (Myotis sodalis) for use in non-invasive sampling. Conserv Genet Resour. 2011;3:243-5.

91. Segelbacher G, Paxton RJ, Steinbruck G, Tronteljs P, Storch I. Characterization of microsatellites in capercaillie Tetrao urogallus (AVES). Mol Ecol. 2000;9:1934-5.

92. Piertney SB, Höglund J. Polymorphic microsatellite DNA markers in black grouse (Tetrao tetrix). Mol Ecol Resour. 2001;1:303-4.

93. Taylor SE, Oyler-McCance SJ, Quinn TW. Isolation and characterization of microsatellite loci in greater sage-grouse (Centrocercus urophasianus). Mol Ecol Notes. 2003;3:262-4.

94. Caizergues A, Rätti O, Helle P, Rotelli L, Ellison L, Rasplus JY. Population genetic structure of male black grouse (Tetrao tetrix L.) in fragmented vs. continuous landscapes. Mol Ecol. 2003;12:2297-305.

95. Oyler-McCance SJ, St. John J, Quinn TW. Rapid evolution in lekking grouse: implications for taxonomic definitions. Ornithol Monogr. 2010;67:114-22.

96. Fike JA, Oyler-McCance SJ, Zimmerman SJ, Castoe TA. Development of 13 microsatellites for Gunnison sage-grouse (Centrocercus minimus) using nextgeneration shotgun sequencing and their utility in greater sage-grouse (Centrocercus urophasianus). Conserv Genet Resour. 2015;7:211-4.

97. Gautier M. Genome-wide scan for adaptive divergence and association with population-specific covariates. Genetics. 2015;201:1555-79.

98. Luu K, Bazin E, Blum MGB. pcadapt: an R package to perform genome scans for selection based on principal component analysis. Mol Ecol Resour. 2017; 17:67-77.

99. Forester BR, Lasky JR, Wagner HH, Urban DL. Comparing methods for detecting multilocus adaptation with multivariate genotype-environment associations. Mol Ecol. 2018;27:2215-33.

100. Keenan K, McGinnity P, Cross TF, Crozier WW, Prodohl PA. diveRsity: an R package for the estimation of population genetics parameters and their associated errors. Methods Ecol Evol. 2013;4:782-8.

101. R Core Team. R: a language and environment for statistical computing. Vienna: R Foundation for Statistical Computing; 2018.

102. Venables WN, Ripley BD. Modern applied statistics with S. fourth. New York: Springer; 2002.

103. Weir BS, Cockerham CC. Estimating F-statistics for the analysis of population structure. Evolution (N Y). 1984;38:1358-70.

104. Hedrick PW. A standardized genetic differentiation measure. Evolution (N Y) 2005;59:1633-8.

105. Oksanen J, Blanchet FG, Friendly M, Kindt R, Legendre P, McGlinn D, et al. vegan: community ecology package. 2017.

106. Jombart T. Adegenet: a R package for the multivariate analysis of genetic markers. Bioinformatics. 2008;24:1403-5.

107. Jombart T, Devillard S, Balloux F. Discriminant analysis of principal components: a new method for the analysis of genetically structured populations. BMC Genet. 2010;11:94.

108. Nei M, Kumar S. Molecular evolution and phylogenetics. New York: Oxford University Press; 2000.

109. Ward JH. Hierarchical grouping to optimize an objective function. J Am Stat Assoc. 1963;58:236-44.

\section{Publisher's Note}

Springer Nature remains neutral with regard to jurisdictional claims in published maps and institutional affiliations. 